\title{
EFFECT OF DIFFERENT RHIZOBIUM STRAINS ON THE GROWTH ATTRIBUTES OF BLACK GRAM
}

\author{
S. K. Nitu, M. M. Ud-Deen ${ }^{1} *$ and S. A. Haider \\ Crop Physiology Laboratory, Department of Botany, \\ University of Rajshahi, Rajshahi-6205, Bangladesh
}

\begin{abstract}
Effects of three different Rhizobium strains on the growth attributes of two black gram varieties (Vigna mungo L. Hepper) revealed differential varietal response due to inoculation with two types of Rhizobium strains. Treatment $\mathrm{T}_{5}$ showed higher values compared to the rest of the treatments. Different growth parameters such as RGR, LAR, RLGR, LAD, LAI, SLA and LWR indicated better results with the inoculation of nodule organism.
\end{abstract}

Key words: Growth attributes, black gram, Vigna mungo, Rhizobium strains

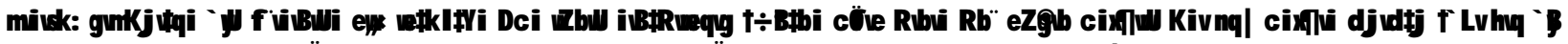

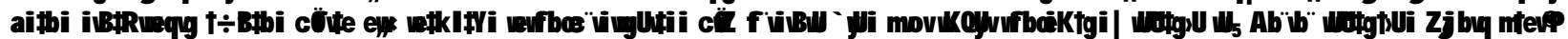

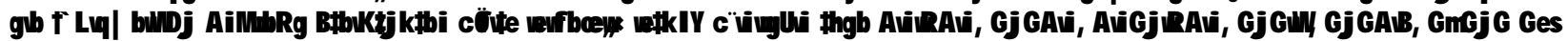

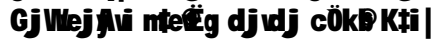

\section{Introduction}

Among the pulse crops grown in Bangladesh black gram (Vigna mungo L. Hepper) is the important one. It is locally known as 'Mashkalai' and belongs to family Leguminosae. Although it is cultivated in many tropical and sub-tropical countries of the world including Bangladesh, a major part of the population of this country does not consume this pulse and thus, suffers from malnutrition due to deficiency of protein. Along with other pulses black gram may play important role in filling up the protein deficiency.

Nitrogen based fertilizers may serve for better growth of crop plants but efforts should be oriented towards augmenting biological nitrogen fixation mediated by microorganisms. An average area of grain legumes like soybeans, beans, or peas provides sufficient protein for 1000-2000 days for one person, whereas an average area of plant materials converted to animal protein like beef and poultry provides only for 75-250 days (Burns and Hardy, 1975). The ratio between chemically fixed nitrogen and biologically fixed nitrogen ranges approximately from 1:4 to 1:2.5 and within biological fixation, the legume fixation is equivalent to or at least half that of industrial fixation (Subba Rao, 1976).

Obligate endophytic enzymes in plant roots and Rhizobium in root nodules by their dual action give benefit to the leguminous plants. Now it is an established fact that nodules on legume roots are responsible for fixing atmospheric nitrogen. It is also evident that in leguminous plants Rhizobium plays important role for nodulation. Taha et al. (1976)

${ }^{1}$ Department of Crop Science \& Technology, University of Rajshahi, Rajshahi; *Correspondence: demonstrated responses of Rhizobium inoculation on some leguminous plants like arhar, Bengal gram, black gram and broad bean. David (1991) reported significant improvement of yield in legume crops due to Rhizobium inoculation. Chowdhury et al. (1998) demonstrated that leguminous crops meet up their nitrogen requirements through biological nitrogen fixation and that is very much dependent on proper growth, development and leghaemoglobin content of the root nodules. The present study examines if the introduced rhizobial strains can colonize, survive and promote the growth attributes of two black gram varieties.

\section{Materials and Methods}

The experiment was conducted in earthen pots under open air condition during the period from September to December, 2007. Two black gram (Vigna mungo L. Hepper) varieties viz. BARI MASH-I and BINA MASH-I procured from the Regional Pulse Research Station of Bangladesh Agricultural Research Institute (BARI), Ishurdi, Pabna, were used. Three strains of Rhizobium viz. RV ${ }^{\mathrm{m}}$ 301, $\mathrm{RV}^{\mathrm{m}} 302$ and $\mathrm{RV}^{\mathrm{m}} 303$ procured from Soil Science Division, BARI, Joydebpur, Gazipur, were used for nodulation in rhizosphere of the two black gram varieties. Fresh soil collected from Botanical garden of Rajshahi University was made free from plant debris and ground into fine particles. Then the soil was mixed proportionately with compost. Before sowing the seeds, 500g triple super phosphate (TSP) and 250g muriate of potash (MP) were added to the soil an experimentation pots. The soil was sandy loam having a $\mathrm{d}$ were dried under sunlight in the $\mathrm{pH}$ value of 7.5. muddeen05@yahoo.com 
The experiment was laid out following a split-split plot design with three replications, where varieties and treatments were assigned as the main plot and sub plot, respectively. Surface area of each pot was $729.3 \mathrm{~cm}^{2}$. Five different treatments were designated as $T_{1}$ (control i.e. with no biofertilizer treated seeds), $T_{2}, T_{3}, T_{4}$ and $T_{5}$. For treatments $T_{2}, T_{3}$ and $T_{4}$, seeds of black gram varieties were inoculated by slurry method with three strains of Rhizobium. For $\mathrm{T}_{5}$ three strains of Rhizobium in a ratio of 1:1:1 were used for inoculation of seeds. The crop was kept free from weeds and no heavy irrigation was applied. Harvest interval method (classical technique) was followed to determine the growth attributes. Experimental data were analyzed statistically following conventional methods.

\section{Results and Discussion}

Growth analyses of two black gram varieties due to treatment with different strains of Rhizobium are presented in Figs. 1-16. RGR increased up to 11-17 DAS and then declined up to 28 DAS but increased again between 35-42 DAS and then declined again in both the varieties (Figs. 1-2). Thus significant effects of treatments, varieties and their interactions were evident. This is similar to Madhok and Dhingra (1951) who found better crop growth under field conditions conducted with inoculation of peas with specific nodules. Increase in plant growth was also reported by Rangaswami and Oblisami (1961) in cowpea when Rhizobium of Medicago sativa was used.

The NAR values in both the varieties increased at the initial stage but after 50-60 days of sowing, on average the values decreased. At the early stage, higher NAR values were found mainly in BARI MASH-1. In BINA MASH-1, the values were found to decline after 65 days of sowing. In this case both variety and treatment were found to show significant effects (Figs. 3-4). However, Luthra et al. (1983) stated that total nodule nitrogen activity in pigeon pea increased with plant growth to reach maximum at flowering (75 days after sowing) and decreased thereafter until maturity (120 DAS). Assimilates produced after flowering were exported to the reproductive structure at the expense of the nodules.
It is suggested that decreased availability of photosynthate to nodules decrease nitrogen fixation.

Starting from a higher value LAR in both the varieties declined steadily with the increase of plant age (Figs. 56). In case of both the varieties, $T_{5}$ showed higher values for LAR between 7-14 DAS. Wallace and Munger (1965) reported highest LAR during the early vegetative stage but later it decreased rapidly with the advancement of age.

RLGR in both the varieties started with a higher value but declined gradually and became negative at the later stage of growth (Figs. 7-8). It might be related with the plant age. However, in the present study $\mathrm{T}_{2}$ showed higher values for RLGR between 32-35 days after sowing. Statistical analysis indicated significant effect of all sources of variation except the interaction of variety and treatment.

In case of leaf area duration (LAD), both the varieties treated with Rhizobium strains showed almost similar results. This character started with low values and increased between 45-50 days after sowing and then declined (Figs. 9-10). It might be related with the nodulation pattern. At the mid age, nitrogen content might be increased causing enhancement of leaf area duration. Varietal response for this character always significant and treatment was found to be significant at 56-63 DAS. At the early vegetative stage, LAD showed lower values but with the advancement of age it showed both higher and lower values based on the nature of different biotic and environmental factors.

The highest value for SLA was found at the first stage of growth in BARI MASH-1. But in BINA MASH-1 it was highest after 35 days of sowing (Figs. 11-12). For this character, all the sources of variation were found to show significant effect at the different stages of growth. In both the varieties after 35 DAS, SLA was found to decrease uniformly. Investigation on cowpea, mungbean and Bengal gram showed that nodulation keeps pace with plant growth until flowering starts (Singh, 1978). The photosynthetic rates were higher in these crops at the seedling and preflowering stages. SLA values decreased with increasing plant dry weight was reported by Chanda et al. (1987). 


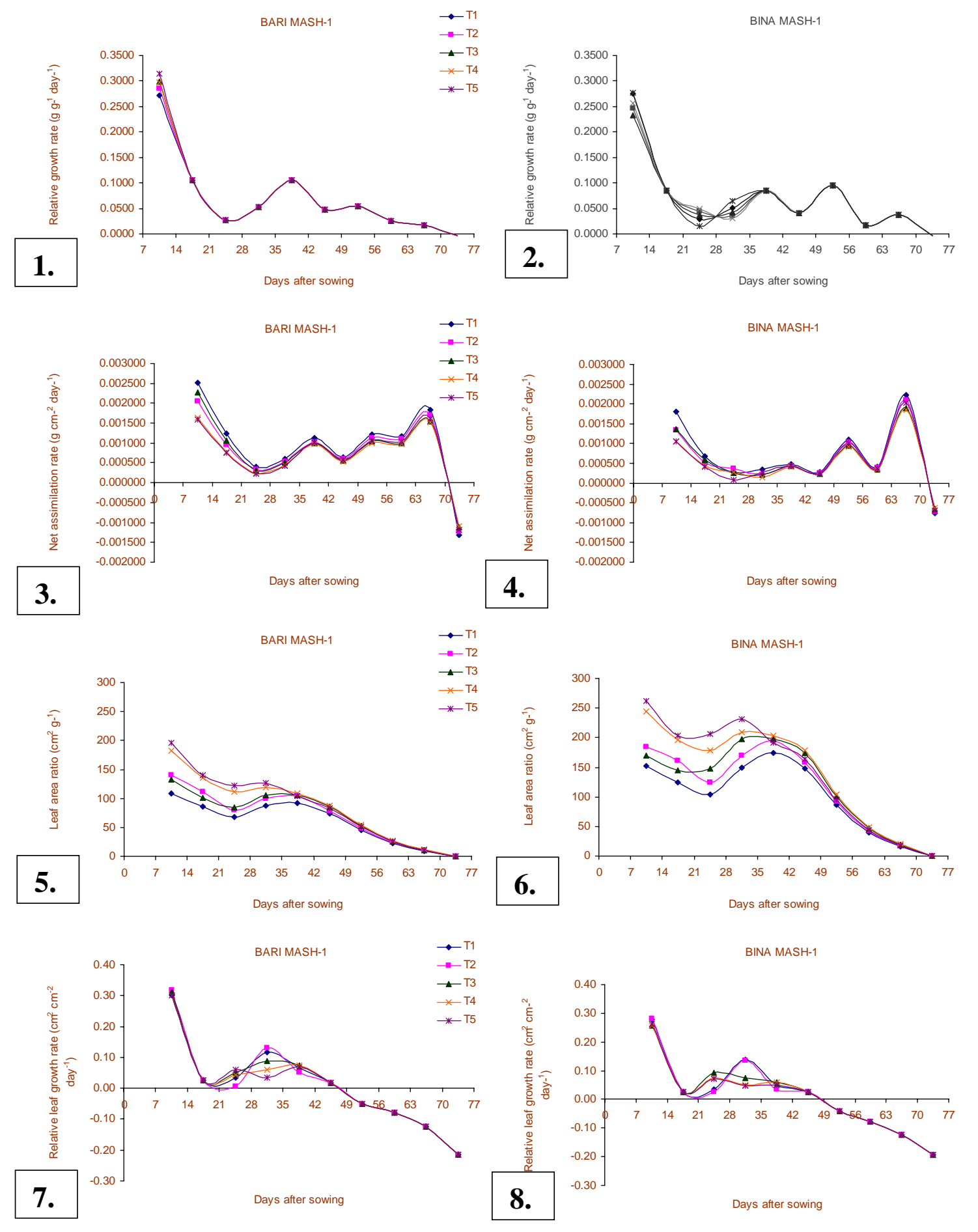

Figs. 1-8. Influence of five different treatments of Rhizobium strains on growth attributes of two black gram varieties at different stages of growth from the original values. 1-2. Relative Growth Rate (RGR), 3-4. Net Assimilation Rate (NAR), 5-6. Leaf Area Ratio (LAR) and 7-8. Relative Leaf Growth Rate (RLGR). 

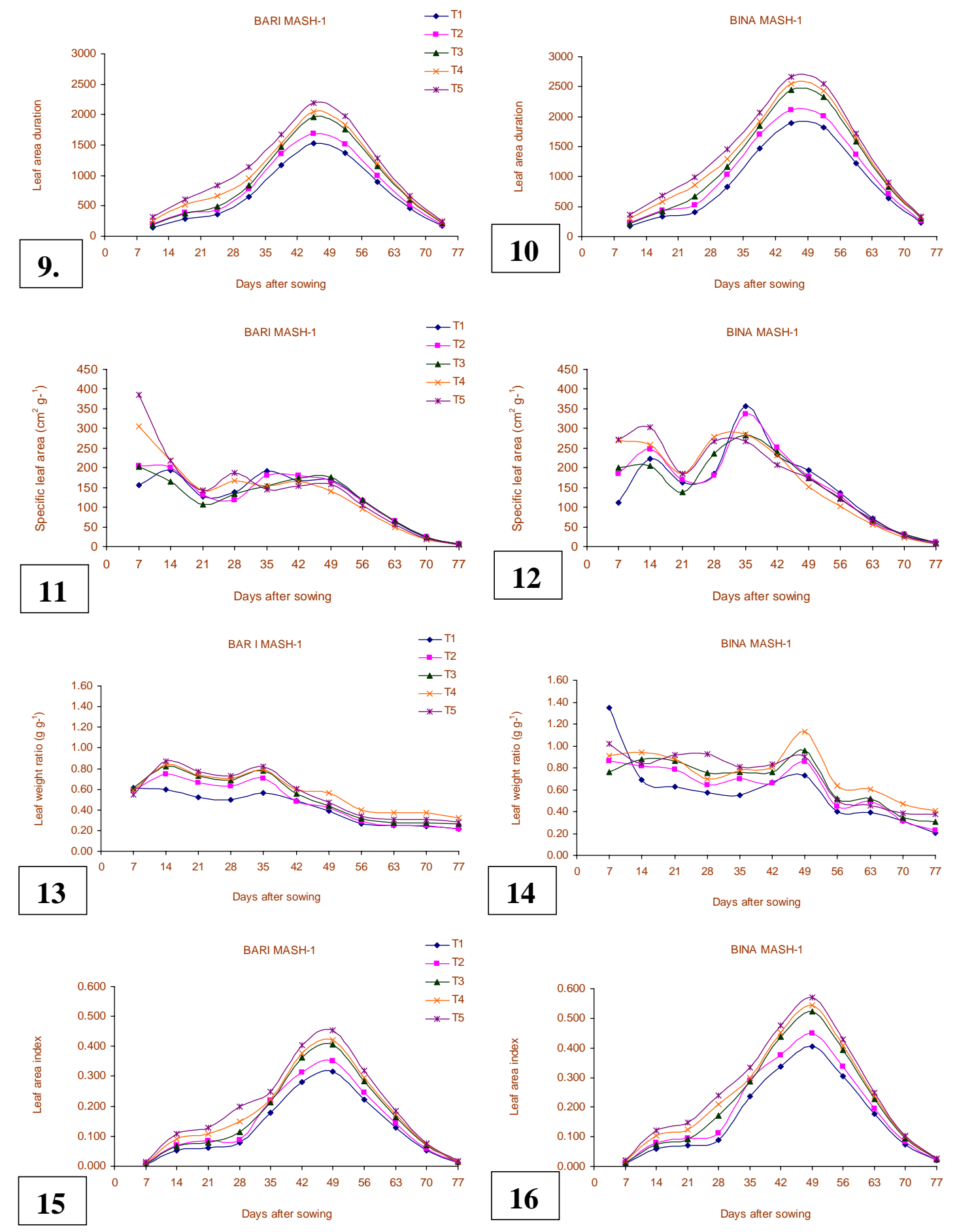

Figs. 9-16. Influence of five different treatments of Rhizobium strains on growth attributes of two black gram varieties at different stages of growth from the original values. 9-10. Leaf Area Duration (LAD), 11-12. Specific Leaf Area (SLA), 13-14. Leaf Weight Ratio (LWR) and 15-16. Leaf Area Index (LAI). 
Starting with a lower value, the LWR values increased slightly for all the treatments in case of BARI MASH-1, but BINA MASH-1 showed higher values for LWR particularly due to $T_{1}$ (Figs. 13-14). In both the varieties, the LWR values declined very slowly, although in case of BINA MASH-1, $\mathrm{T}_{4}$ showed higher LWR at 49 DAS. The LWR values might be increased due to the increase of leaf weight. In the present study, the LWR values declined very sharply with the increase of plant age.

In both the varieties of black gram, starting with very low value at 14 DAS, LAI value was high at 49 DAS, due to five treatments with Rhizobium strains (Figs. 1516). However, the values in both the cases declined very rapidly with the increase of age. Almost similar results due to different factors were reported by Sivakumar et al. (1979) and Rabindranth et al. (1983) in different crops. Pandey et al. (1981) stated that senescence and abscission of the older leaves might cause the depletion of LAI at the later stages of growth.

\section{Conclusion}

In the present findings three different Rhizobium strains responded to different growth attributes of black gram. The combined dose $\left(T_{5}\right)$ responded better compared to that of other treatments. All the growth parameters studied hare were found to show better results due to nodulation.

\section{References}

Burns RC, Hardy RWF. 1975. Nitrogen Fixation in Bacteria and Higher Plants. Springer Verlag, New York. pp. 26-30.

Chanda SV, Joshi AK, Vishnav PP, Singh YD. 1987. Growth analysis using classical and curve-fitting methods in relation to productivity in pearl millet (Pennisetum americanum L.). J. Agron. Crop Sci. 159: 312-319.

Chowdhury MU, Ullah MH, Afzal MA, Khanam D, Nabi SM. 1998. Growth, nodulation and yield of cowpea as affected by Rhizobium inoculation on hilly region. Bangladesh J. Agric. Res. 23(2): 195-203.
David MS. 1991. Effect of solinization, Rhizobium inoculation, genotypic variation and $\mathrm{P}$ application on dry matter yield and utilization of P by pea (Pisum sativum L.) and lentil (Lens cilinaris Medic). J. Nuclear Agril. Biol. 19(4): 227-231.

Luthra YP, Sheoran IS, Singh R. 1983. Ontogenic interaction between photosynthesis and symbiotic nitrogen fixation in pigeon pea. Ann. Appl. Biol. 103: 549-556.

Mahhok M, Dhingra LR. 1951. Effect of inoculation with specific nodule organism on the growth of peas. Proc. Indian Sci. Congr. 38: 170.

Pandey RP, Nair PKR, Tiwari JP. 1981. Correlation of morphophysiological and sink parameters in cow pea. Indian J. Agric. Sci. 51: 221-224.

Rabindranath P, Shiv Raj A. 1983. Effect of moisture stress on growth, yield and yield components of field-grown sorghum varieties having glossy and non-glossy leaves. Indian J. Agric. Sci. 53: 428-430.

Rangaswami G, Oblisami G. 1961. Quantitative studies on nitrogen fixation by five legume nodule bacteria. $J$. Annamalai Univ. 23: 119-124.

Singh SD. 1978. Effect of Rhizobiam inoculation on nodulation and yield of moong (Vigna radiata Wilczek). Ann. Arid Zone 16: 79-84.

Sivakumar MVK, Seetharama N, Singh S, Bidinger FR. 1979. Water relations, growth and dry matter accumulation of sorghum under post-rainy season condition. Agron. J. 71: 843-847.

Subba Rao NS. 1976. Field response of legumes in India to inoculation and fertilizer application. In: Symbiotic Nitrogen Fixation in Plants. ed. P.S. Nutman, pp. 255268, Cambridge Univ. Press, Cambridge.

Taha SM, Mahmoud SZ, Salem SH. 1976. Effect of inoculation with rhizobia on some leguminous plants in UAR. I. Phosphorus manuring. J. Microbiol. United Arab Repub. 2: 17-29.

Wallace DM, Munger HM. 1965. Studies on the physiological basis for yield differences. I. Growth analysis of six dry bean varieties. Crop Sci. 5: 343-348. 